\title{
Strategies for family engagement in evidence-based programmes: A meta-synthesis of systematic reviews from a social casework approach
}

\author{
Lluc Nevot-Caldentey ${ }^{1,}$ Carmen Orte Socías ${ }^{1}$, Lluís Ballester Brage ${ }^{1}$
}

\begin{abstract}
This paper explores the role of social work practice in youth risk prevention through evidence-based interventions, such as the Strengthening Families Programme. It begins by analysing the aetiology of social work practice in prevention and the theories that aim to explain social work practice as one of the most important disciplines for meeting the skill development requirements of risk prevention. Research has shown that evidencebased interventions applied at the family level can delay the onset of substance use. Various studies have backed working with these kinds of systems to ensure the effectiveness of interventions aimed at reducing substance abuse; however, family participation has also been shown to be one of the disadvantages of this kind of intervention. For this reason, the main goal of the present research is to identify the most effective strategies for engaging families in the context of social casework. We present a meta-synthesis of two systematic exploratory reviews of scholarly articles concerning family involvement, adherence, and findings that lead to achieving coupling. We discuss the family factors that social workers should consider in order to ensure that different members of family systems commit to building supportive relationships.
\end{abstract}

Keywords: social work; evidence-based programs; family engagement; Family Competence Program; Juvenile Prevention

1. Department of Pedagogy and Specific Didactics (GIFES). Universitat de les Illes Balears

Address for correspondence: lluc.nevot@uib.es

Date of first (online) publication: 18th December 2019 


\section{Aetiology of social work in prevention in Spain}

The empirical community has historically evidenced the value of professional education and training in ensuring the efficacy of putting evidence-based programmes into practice (Hoge, Huey and O'Connell, 2004; Orte, Ballester, Amer and Vives, 2014; Orte, Ballester, Pascual, Gomila and Amer, 2016; Orte, Ballester, Amer and Vives, 2017; Axford et al., 2018). Social work boasts a long history of leadership in prevention work (Siefert, 1983) and is well positioned to respond to this contemporary need.

The first Spanish School of Social Work was born in Barcelona in 1891. This School was intended to provide technical training for those who decided to intervene to improve society. Social work emerged as a different profession through the efforts of European countries to professionalize attention to the most disadvantaged. Through the Plan Concertado para el Desarrollo de Prestaciones Básicas de Servicios Sociales of 1988, the challenge of consolidating the Social Services model in Spain was addressed. It was introduced a preventive work of situations of need for intervention of specialized services. The implementation of the system served to strengthen educational systems and specialized services (Paniagua, Lázaro and Rubio, 2010).

In 1985 the National Drug Plan (PNSD) was created to coordinate the public policies related to the field in Spain. Social Work was born in Spain in the nineteenth century linked to medical science. Social Workers point out that in 1978 the World Health Organization (WHO) develops a new paradigm in the health care which implies accentuating the social dimension of health disciplines (WHO, 1978).

Currently, drug addiction is one of the most complex and problematic social phenomena (Martín, 2009). Drug use has two links with the social area: on the one hand, drug addicts become consumers for microsocial reasons (family educational style, family breakdown or poorly resolved family conflicts) or macrosocial (dominant social values, speeches around the issue of drugs, etc.) on the other hand, drug use causes a deterioration of collective well-being due to the social problems involved. They often lead to social exclusion and marginalization.

Gutierrez (2007) indicates that in the field of drug addiction, Social Work professionals are part of a group of social mediators which constitute a preventive strategy in the community'. Prevention aims to detect and reduce risk factors, and to enhance protection factors. Prevention contemplates the phenomenon of drugs as a complex social phenomenon in which the factors associated with substances, the person, the social and environmental context are contemplated (Jiménez, 2016). The communitarian currents in the Social Work are introduced in Spain at the end of the 70s. However, at present, it is reflected on the scope of the Community Social Services because in practice the individualized attention and a low capacity for community intervention dominate (Gutiérrez, 2007). 


\section{Prevention as a driver of change, development, and social cohesion}

Prevention science seeks to alter malleable risk - promotion and protection factors in individuals and environments - with the hope of changing the likelihood of future problems arising. Prevention is different from treatment in that it is aimed at communities, groups, or individuals that, without meeting the factors to diagnose a disorder or to commit a crime, benefit from interventions that reduce the likelihood of developing a disorder or criminal behaviour in the future ( $\mathrm{O}^{\prime}$ Connell, Boat and Warner, 2009).

This helps explain why the development of a single infrastructure is important for the dissemination of effective prevention. Preventive interventions seek to reach the population that does not necessarily interact with clinically skilled professionals or with the services aimed at treating mental, emotional, or behavioural problems.

Preventive services can be provided to the population (universal prevention); to those at risk of problems due to exposure to risk factors but who have not yet experienced a problem (selective prevention); or to those who have shown signs or early symptoms of mental disorders, or emotional or behavioural problems, but who have not yet developed a diagnosable disorder or criminal behaviour (indicated prevention) (O'Connell, Boat and Warner, 2009).

Substance use is linked to poor academic performance, job instability, teenage pregnancy, delinquency, violence, crime, and transmission of sexually transmitted diseases (Howell, 2009; O'Connell, Boat and Warner, 2009; Axford et al., 2018). As many of the same risk factors predict a series of different negative results, it is possible to prevent these different problems by tackling shared indicators.

By pooling information and resources and selecting proven and effective policies and programmes that address local needs, community coalitions can ensure the adoption of proven and effective prevention activities, improve community participation in these initiatives, and increase the likelihood of sustainability (Hawkins and Shapiro, 2011).

\section{Evidence-based prevention programmes}

In the last 30 years there have been many diverse breakthroughs in the development and testing of prevention policies, practices, and programmes. Effective tools for preventing mental health, emotional, and behavioural problems in young people have been identified through controlled studies using rigorous experimental designs (O'Connell, Boat and Warner, 2009; Hawkins and Shapiro, 2011).

Lists of these programmes are available on the Internet (colorado.edu/cspv/ blueprints; ncadi.samhsa.gov/features/ctc/resources.aspx). However, according to 
Woolf (2006), the design of these effective prevention strategies often overlooks strategies for addressing surrounding realities, close to the disorder that is to be prevented.

Systems for working with mental health, emotional, and behavioural disorders are maintained via an infrastructure that provides funding, access, and training in the workplace. Meanwhile, their translation into preventive approaches, effective in their generalised praxis, requires the development of an infrastructure that is large enough to address prevention within the participatory environment (Cullen and Jonson, 2009; O'Connell, Boat and Warner, 2009; Woolf, 2006).

Balas and Boren (2000) speculated some time ago as to the reasons why the advances achieved through research could not be successfully extrapolated to generalised practice. They suggested:

1. scientific research often isolates itself from certain realities in order to maintain the integrity of the scientific process;

2. scientific theories tested with specific populations may fail when generalised to poorly studied populations and environments;

3. proven and effective practices might pose difficulties in providing access to their potential users;

4. proven policies, programmes, or practices may be poorly articulated, may be difficult to replicate faithfully;

5. attention is not paid to the needs, values, and proprieties of the people and communities that could use these programmes or practices;

6. attention is not paid to the mechanisms of understanding for change towards sustainable systems, or the development of a community infrastructure that will enable effective policies, practices, and programmes to be supported.

Effectiveness standards and dissemination research trials developed by the Society for Prevention Research (Gottfredson et al., 2015) emphasised the fact that prevention policies, practices, and programmes must be tested in real environments; providing guidelines that highlighted the need to describe research samples in detail in order to inform generalisations to diverse populations. These guidelines require the developers of prevention programmes to create manuals and provide training and technical assistance to support quality use and help in the replication of prevention technologies.

Professionals who conduct efficacy and dissemination trials by following quality standards cannot isolate their practice from individuals and organisations. Therefore, community infrastructures are required that can support proven and effective prevention policies, practices and programmes which, in turn, address the needs, values and priorities of the individuals, organisations, and communities using these preventive interventions. 


\section{The role of family engagement in risk prevention}

Evidence indicates that the consequences associated with the consumption of toxic substances may have a costly effect in the long term in both families and communities (Rankin et al., 2016), and that one of the most frequent causes of juvenile morbidity and mortality is associated to substance use. Most people who use alcohol and cigarettes try these substances for the first time in their adolescence (58\% are under 18 and $81 \%$ under 21 , with a mean global age of 17.4 years) according to data supplied by the Substance Abuse and Mental Health Services Administration (SAMHSA, 2018).

Rankin et al. (2016), amongst others, demonstrated that substance prevention programmes applied in the family environment managed to delay substance use initiation. Several studies support working with this system in order to ensure the efficacy of interventions attempting to reduce substance abuse. Kolovelonis, Goudas and Theodorakis (2016) maintain that the inclusion of important social agents such as parents or teachers improves the effectiveness of consumption prevention programmes. Interventions in which parents are involved increase the effects of the intervention by delaying the time at which the first contact with said substances takes place (Bodin and Strandberg, 2011; Segrott et al., 2014; Ennett et al., 2016; Koning and Vollebergh, 2016; Rankin et al., 2016).

Spoth, Guyll and Shin (2009) add that several factors are associated with the exposure to the risk of consumption identified in the family, such as parenting practices. In fact, the test conducted by Ennett et al. (2016) showed how parental training when it comes to instilling and strengthening attitudes and behavioural guidelines against juvenile consumption managed to modify certain cognitive factors.

One of the most widely supported parental competence programmes due to its effectiveness and efficacy, based on empirical evidence, which meets the requirements to guarantee the prevention of adolescent consumption is the Strengthening Families Program) (Kumpfer and De Marsh, 1985; Kumpfer, DeMarsh and Child, 1989; Spoth et al., 2002; Coombes et al., 2009).

The Family Competence Program (FCP) is established both universally and selectively as a prevention strategy that acts on risk factors that arise during childhood and adolescence based on work on the family as a whole (Orte, Ballester and Amer, 2015; Nevot, Ballester and Vives, 2018).

This adaptation is based on the original proposal programmed in North America; the Strengthening Families Program (SFP) (Kumpfer and De Marsh, 1985; Kumpfer, DeMarsh and Child, 1989); a programme classified as a model by the Substance Abuse and Mental Health Services Administration (SAMHSA).

The Social and Educational Training and Research Group (GIFES) decided to channel the necessary validation process in order to test the effectiveness of its applications in the Spanish population, developing their task based on evaluations of the process, results, and control of possible sources of bias (Orte and Gifes, 2005a, 2005b; Orte, Touza and Ballester, 2007; Ballester, Nadal and Amer, 2014). 
In the process of detecting the weaknesses arising in the applications of the SFP, one of the main causes of failure was identified as being related to the loss of family engagement during the implementation process (Axford, Lehtonen, Kaeoukji, Tobin and Berry, 2012). This weak point has been also found in other evidence-based programmes such as the Family Check-Up (FCU) (Forgatch, Bullock and Patterson, 2004; Bullock and Forgatch, 2005). Dishion, et al., (2008) found that the volume of participants that became effectively engaged in the implementation reached only $25 \%$ of the volume of initially expected participants.

Following the identification of the weak point characterising evidence-based interventions (EBI) aimed at the prevention of risks acting in the family environment, based on the application of incentives, participation rates can be increased to $75 \%$ of the total volume (Lewis et al., 2012).

In several family motivation tests, greater retention rates were identified in experimental groups where incentives were applied; along with an improvement in the cost-benefit balance of the programmes, and larger effect sizes than when they were applied at the individual level (Gewin and Hoffman, 2016; Kumpfer, Kumpfer, Magalhães and Xie, 2016). Prinz and Miller (1996) defined incentives as implementation strategies that positively reinforce retention.

Further, Orte, Ballester and Amer (2015) showed that family engagement influences the improvement of the results of family competence skills in the long term. Hence, family engagement strategies are established as a favourite preventive strategy in order to ensure the improvement of the effectiveness of the SFP-FCP.

\section{Method}

The present study is aimed at determining what techniques of adherence and family engagement, in programmes or interventions aimed at the prevention of problembehaviours in the stages of childhood and adolescence, are the most effective. This aim, in turn, corresponds to the fourth aim of the Research Project 'Validación del Programa de Competencia Familiar Universal 10-14 en España [Validation of the Universal Family Competence Program 10-14 in Spain] (120125 - I+D relativa a las Ciencias Sociales financiada con FGU)' operationalised in 'Evaluar la adherencia de los padres e hijos participantes, a lo largo de las sesiones que componen el programa' [Evaluating the adherence of parent and child participants, during the sessions making up the programme].

The purpose for which it is established is based on the need to increase the volume of participants in the Family Competence Program 10-14 at times of recruitment and in maintaining adherence.

This study presents the first step carried out to identify the most effective family engagement techniques: two exploratory systematic reviews of the existing literature 
concerning family engagement and adherence correspond to the first goal established in the project to achieve goal three therein.

To carry out a review of the existing literature in terms of design and evaluation of prevention programmes.

\section{Inclusion and exclusion criteria}

The search was limited to a review of journal articles, as their publication is established as the main aim of the international empirical community when it comes to disseminating the most recent, innovative research results. Articles published between 2007 and 2017 were selected, given the interest in knowing the current findings regarding the subject of study. The search was not limited by language so as to ensure access to publications with the greatest international impact. Under these premises, the fundamental inclusion criterion was that the reviewed documentation corresponded to the express interests entailed in the research aims.

Four databases were extracted: EBSCOhost, SCOPUS, Web of Science, and Cochrane Database Review. The key words in the search were:

'family prevention', 'parental engagement' and 'addictions' combined with:

1. Search terms were used to access the literature related to family prevention in prevention programmes. Terms and truncations were: 'famil*', 'prevent*'. The Boolean operator used between key words was 'AND'.

2. Keys to access research related to family engagement were: 'retention*', 'retain*', 'adhe*', 'engag*', 'compliance*', 'attr*'. The logic gate for article entries in this case was 'OR'.

3. Words that made it possible to access results related to prevention interventions linked, preferably, to addictions: 'drug*', 'addict*', 'tobac*', alcohol*', 'cannab*'. The operator applied was again 'OR'.

Through an indirect search, reference lists of review manuals and prior studies were analysed in order to include additional studies that met the aforementioned inclusion criteria. After reviewing and screening the articles in the databases, in short, the chosen studies scanned in full text constituted the final sample ( $\mathrm{n}=141)$.

\section{Meta-synthesis procedure}

Database selection and initial screening based on summarised reading were ranked equally for both systematic reviews, which tentatively enabled studies to be found in terms of engagement from two different perspectives: firstly $(n=141)$ articles on strategies to promote the engagement or adherence of families in interventions of 
any sort: the intention was initially to systematise all the tools defended in the empirical literature according to their effectiveness in engaging families in social and educational interventions aimed at preventing risks in minors.

In a second review, emphasis was placed on the characteristics of the studies, in this case of a quantitative nature, regarding the relationship existing between engagement techniques and EBI and the need to find out what current techniques are proven to be the most effective $(n=12)$.

The criteria under which the meta-synthesis took place (M-S) are specified in:

1. Identifying the studies concerning family factors in which the Social Worker can serve to pose interventions that will ensure the adherence and engagement of the family throughout the process.

2. Pointing out the family and community factors in interaction with professional efforts that can enable family commitment; and improving systematic training of the professional in handling preventive skills.

Figure 1. Article screening tree based on their selection in databases

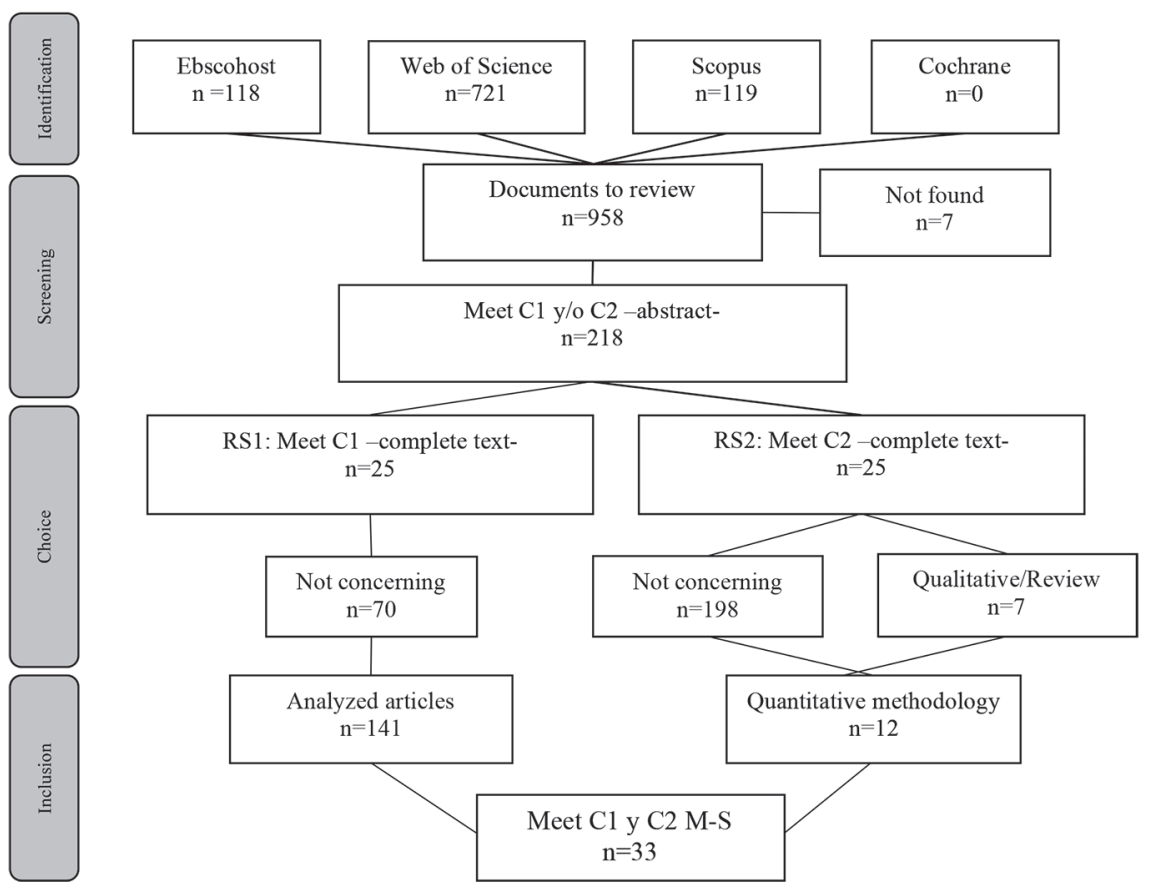

Note. As illustrated in the figure, the final number of articles analysed with useful contributions amounted to a total of $n=141$ in Systematic Review 1 (SR1) and $n=12$ in Systematic Review 2 (SR2) 


\section{Results}

Table 1 shows the factors that improve family involvement according to the different studies included in the review. On the other hand, as can be appreciated on Table 2 , studies analyzing family engagement are described depending on the study (author/s and year), sample, the kind of intervention, the aim (if family involvement is the primary or the secondary goal of the study) the measure/s implemented, the impact of the intervention, the methodological classification (evaluating the degree of adequacy of the results to the goals of the systematic review) and limitations of the study with regards to the aim of the review.

Table 1. Family factors that facilitate recruitment

\begin{tabular}{|l|l|l|}
\hline Factor & $\mathrm{n}$ & Intervention proposal to improve involvement \\
\hline $\begin{array}{l}\text { Family } \\
\text { awareness about } \\
\text { the problem }\end{array}$ & 4 & $\begin{array}{l}\text { Knowledge about the problem; understanding needs linked to } \\
\text { preventive intervention; understanding experiences and needs } \\
\text { of marginalized groups; awareness about the problem; increasing } \\
\text { the sense of responsibility; parental motivation in subsidiary } \\
\text { care (overcoming stigma effects); greater control and acceptance; } \\
\text { generation of interest }\end{array}$ \\
\hline $\begin{array}{l}\text { Preparation for } \\
\text { treatment; the } \\
\text { professional and } \\
\text { the family are } \\
\text { motivated }\end{array}$ & 7 & $\begin{array}{l}\text { Understanding of the contents and the practice of the } \\
\text { program; guide for professionals for informed decision } \\
\text { making; comprehensive training trainers in communication } \\
\text { skills; motivation or team 'coaching; therapeutic partnership; } \\
\text { psychoeducation of attitudinal improvement (PAI); underlying } \\
\text { participation mechanisms }\end{array}$ \\
\hline $\begin{array}{l}\text { Logistical } \\
\text { support }\end{array}$ & 8 & $\begin{array}{l}\text { Attention under socioeconomic level; attention to the 'lack of time' } \\
\text { (2), 'lack of resources' and 'lack of knowledge; economic incentive } \\
\text { (2); family/resource incentives (3); social support, transportation, } \\
\text { housing, beliefs, relationship training / participant, commitment }\end{array}$ \\
\hline $\begin{array}{l}\text { Perceived value } \\
\text { and benefit of } \\
\text { the service }\end{array}$ & 9 & $\begin{array}{l}\text { Attention to factors low socio-educational level; facilitate } \\
\text { connection between sessions; advice; increase male participation; } \\
\text { communication partner (2); access to social support and formal } \\
\text { services; improve of the confidentiality and stigma reduction; } \\
\text { attention to family and child factors }\end{array}$ \\
\hline $\begin{array}{l}\text { Welfare of the } \\
\text { caregiver; good } \\
\text { management } \\
\text { services }\end{array}$ & 4 & $\begin{array}{l}\text { Diagnostic and individualized preventive strategies (2); support } \\
\text { and personalized control; skills adaptation stress; participation } \\
\text { and retention parents; greater satisfaction parents }\end{array}$ \\
\hline expectations & 1 & $\begin{array}{l}\text { Informative packets for students and parents and proactive } \\
\text { family information sessions; understanding the objectives of the } \\
\text { intervention }\end{array}$ \\
\hline
\end{tabular}




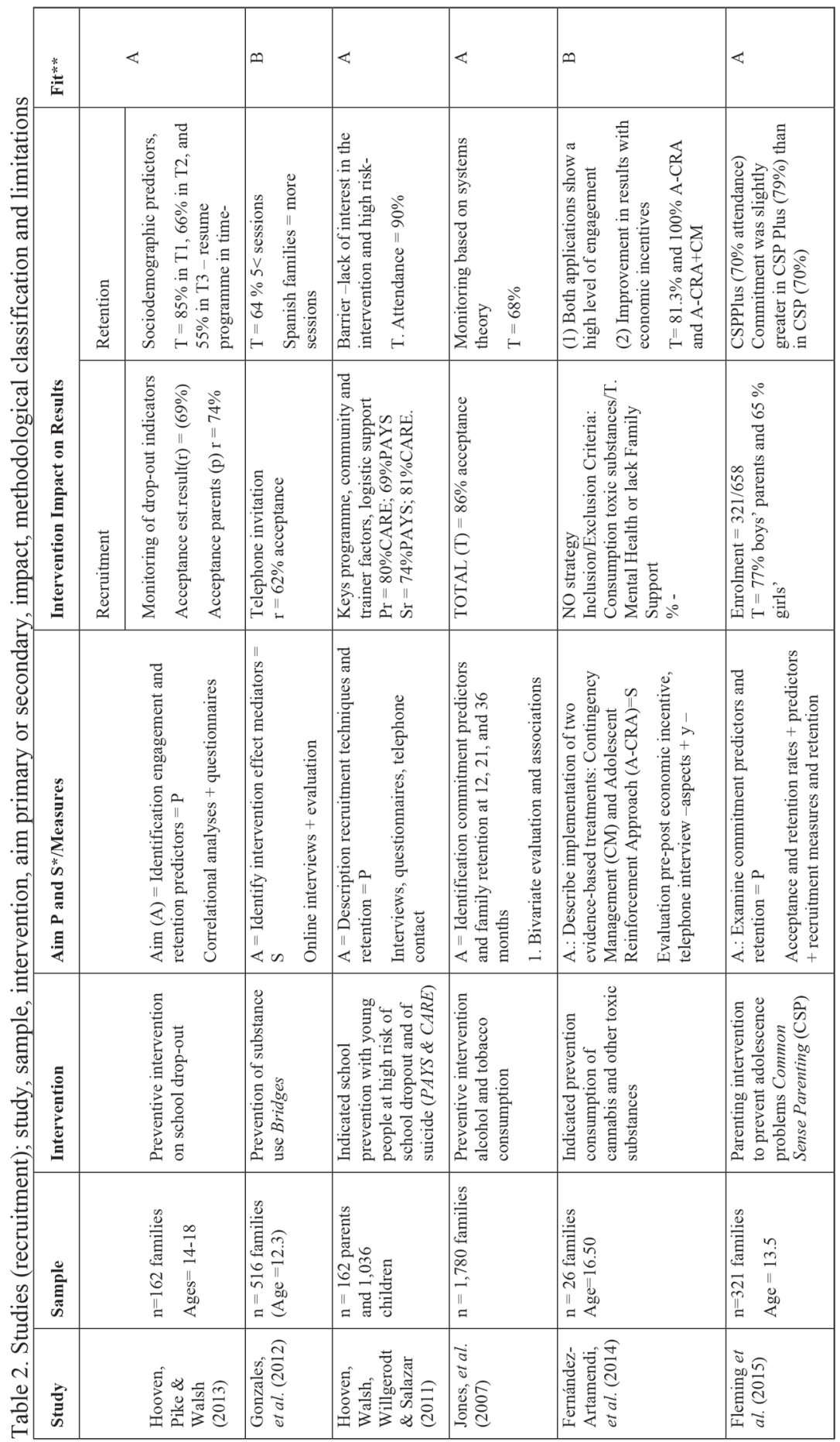




\begin{tabular}{|c|c|c|c|c|c|c|c|}
\hline & \multicolumn{2}{|c|}{$\varangle$} & $\infty$ & $\mid<$ & $\ll$ & $\infty$ & $\varangle$ \\
\hline & & 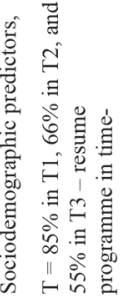 & 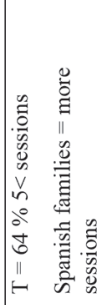 & 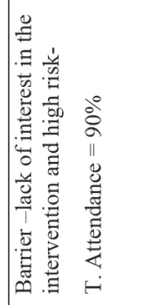 & 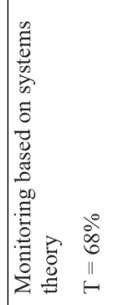 & 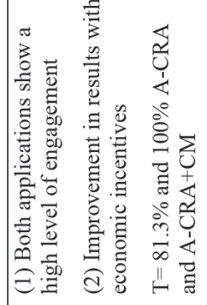 & 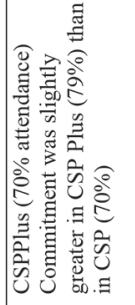 \\
\hline & & 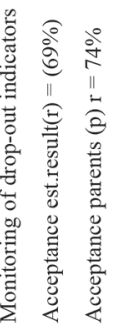 & 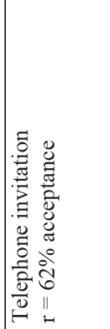 & 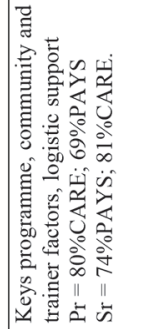 & 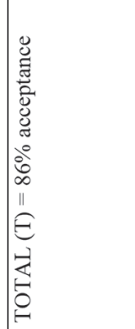 & 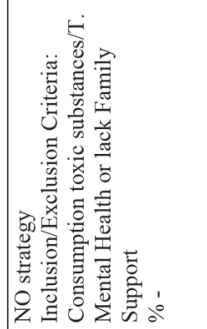 & 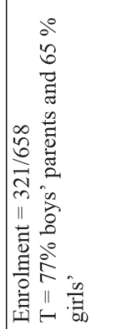 \\
\hline & & 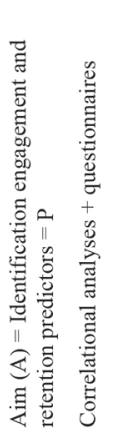 & 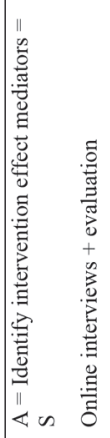 & 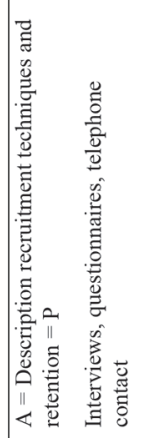 & 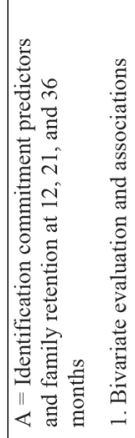 & 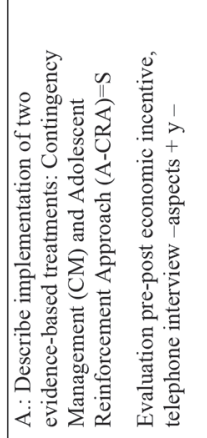 & 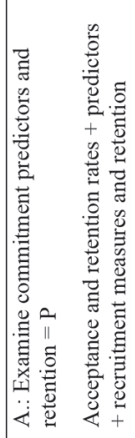 \\
\hline & & 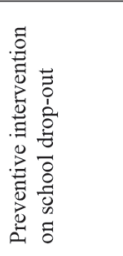 & 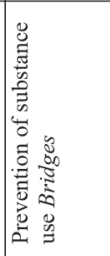 & 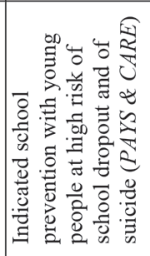 & 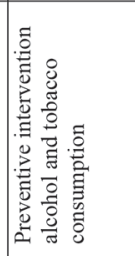 & 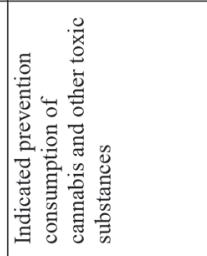 & 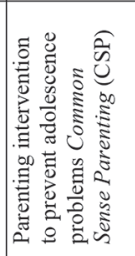 \\
\hline & & 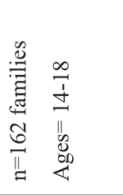 & 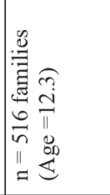 & 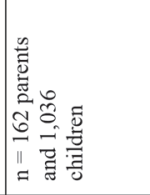 & 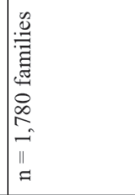 & 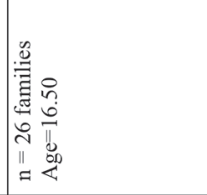 & 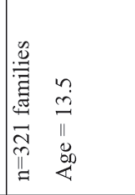 \\
\hline & & 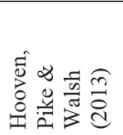 & 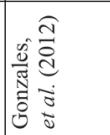 & 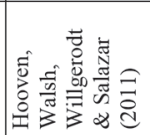 & 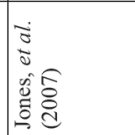 & 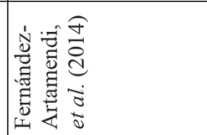 & 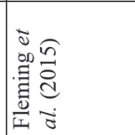 \\
\hline
\end{tabular}




\section{Thematic synthesis}

Of the studies that matched to $\mathrm{Cl}$ of this meta-synthesis ( $\mathrm{n}=33$ ), a series of factors typical of the family system ( $n=33$ ) were extracted, which make it possible to establish intervention lines that improve effectiveness, in this case of EBI, such as the ones related to the Family Competence Program (FCP).

The level of awareness acquired by the family as regards the problem, the joint preparation of the Social Worker and of the family in terms of developing the programme, the logistic support they receive, perceived value and expected benefit based on the likelihood of benefitting from the service, wellbeing of the parents with respect to the intervention, and the expectations with which the family undergo the intervention are some keys of identified effectiveness in family engagement.

In response to $\mathrm{C} 2$, regarding quantitative type studies, whose classification in $\mathrm{A}$ or B served to define the studies with greater or lower level of contribution to the study topic in relation to the methodological quality with which they were developed, several individual and/or family factors to be considered were extracted.

The study by Hooven, Pike and Walsh (2013) indicated that individual characteristics of participants might encourage the implementer as to the likelihood of losing the engagement facilitator link. They propose its identification through prior monitoring of indicators of disconnection.

In relation to retention, they point out differences in engagement strategies to be applied depending on certain factors such as age, education, and family composition. Fleming et al. (2015) explained that income level and parental education level, younger age of the child/ren, and poverty of the affective quality of the parent-child relationship were predictors of lack of attendance in the initial moments of the process.

Jones et al. (2007) examined the influence of ecological context, reaching the conclusion that family factors, but not extra-family ones, were linked to family participation longitudinally over time.

Access barriers were also pointed out as an element of loss of participation (Byrnes, Miller, Aalborg and Keagy, 2012). Low socioeconomic families have limitations typical of the neighbourhood - disorganised neighbourhoods - that generate disadvantages when it comes to accessing preventive care services.

Gonzales et al. (2012) mention the need for acculturation in the design of interventions. Kumpfer, Xie and O'Discroll (2012) also referred to the need for cultural adaptation. Nevertheless, they highlighted the need not to change the contents of EBI in their process of adaptation.

Hooven, Walsh, Willgerodt and Salazar (2011), meanwhile, highlighted some characteristics of interventions for their efficacy: interactive activities - respecting autonomy and privacy; flexibility of the intervention - time, location and frequency; and transmission of respect - honesty of the social worker, ethical considerations and avoiding prejudices.

Al-Halabí and Errasti (2009), Fernández-Artamendi, Fernández-Hermida, 
Godley and Secades-Villa (2014) showed the effectiveness of using monetary or material incentives. Miller, Aalborg, Burnes, Bauman and Spoth (2012) explained the improvement in the impact of the intervention in terms of results, retention, and commitment depended on the family's perception of need for intervention.

Further, Byrnes, Miller, Aalborg and Keagy (2012) identified that the fact that the Social Worker considers the family when making decisions concerning the implementation was, in fact, considered a factor of family engagement.

\section{Conclusions}

This meta-synthesis of two systematic reviews was carried out for the purpose of answering the study question as to the most effective parental engagement strategies in order to increase family participation rates in evidence-based programmes.

Thus, the goal was to direct the study to finding out what family factors Social Workers should take into account, when it comes to creating an engagement encouraging aid alliance for the different members of the family system.

Based on the meta-synthesis of the results of SR1 and SR2, a set of techniques or strategies were identified which give rise to implications for future implementation proposals, the tools of which can be grouped in both factors for which it was decided to undertake this study: in family factors and in factors related to the Social Worker.

Amongst family-related factors, Fleming et al. (2015) and also Hooven, Pike and Walsh (2013) identified a continuum of disconnection indicators, which help the Social Worker, in this case the implementer of EBI, in the early identification of dropout items. The results identified in SRl provide some keys to avoiding family dropout.

Social Workers from the very first meetings with the family can work with the family system by raising awareness of problems of emotion or behaviour or the disorders it is possible to prevent through preventive interventions. In turn, the Social Worker-client system can be prepared, by talking, acquiring prior awareness of the type of intervention, and of the contents that will be worked on in the programme or evidence-based intervention.

The studies evidence the need for participants to understand the value and added benefit to their situation of the appropriate use of the preventive EBI they are going to participate in.

Furthermore, the Social Worker should acquire a sufficient standard of competence in handling EBI and characterise the population to be aimed at, in order to ensure any cultural adaptations that might be necessary and the handling of the ethical considerations that might govern its implementation.

Another key to family involvement is related to the logistic support the family will receive. The studies evidence that the families with the greatest need to benefit 
from preventive interventions might be the ones that, in turn, have the greatest difficulties in accessing the programme - need for transport or childcare service.

Hence, the anticipation, by the trainer, of the support needs that might arise in the families is also an element that will reduce the likelihood of losing participants.

Finally, the need is highlighted for the implementer to lay down prior foundations in order to create a relationship of cooperation and trust, to generate a climate of family wellbeing that is necessary to promote change, and to transmit to the families that their expectations are recognised by the professional involved in the aid relationship.

The meta-synthesis of the systematic reviews conducted on techniques that enable engaging the family as a whole in EBI was necessary in order to understand the ways of preventing lack of enrolment and/or loss of participants during the implementation process.

Moreover, this study makes it possible to convey the results of both studies, in response to the first goal of the fourth aim of the project 'Validación del Programa de Competencia Familiar Universal 10-14 en España [Validation of the Universal Family Competence Program 10-14 in Spain] (120125 - I+D relativa a las Ciencias Sociales financiada con FGU)' which is operationalised in 'Evaluar la adherencia de los padres e hijos participantes, a lo largo de las sesiones que componen el programa' [Assessing adherence of parent and child participants, throughout the sessions making up the programme].

Our purpose focused on highlighting the evidence-based lines of praxis that will enable us to translate factors from theory into the planning of strategies which, after their necessary validation, can serve to improve the quality of the application of evidence-based preventive programmes and, specifically, the application of the Family Competence Program.

\section{References}

Al-Halabí, S. and Errasti, J. M. (2009) Use of small incentives for increasing participation and reducing dropout in a family drug-use prevention program in a spanish sample, Substance Use \& Misuse, 44, 1990-2000

Axford, N. Lehtonen, M. Kaoukji, D. Tobin, K. and Berry, V. (2012) Engaging parents in parenting programs: Lessons from research and practice, Children and Youth Services Review, 34, 2061-2071

Axford, N. Warner, G., Hobbs, T. Heilmann, S., Raja, A. Berry, V., and Bjornstad, G. (2018) The effectiveness of the inspiring futures parenting programme in improving behavioral and emotional outcomes in primary school children with behavioural or emotional difficulties: study protocol for a randomised controlled trial, BMC Psychology, 8, 1-11

Balas, E.A. and Boren, S.A. (2000) Managing clinical knowledge for health care improvement, 
in van Bemmel, J.H., McCray, A.T. and Alexa, T. (Ed.), Yearbook of Medical Informatics: Patient-Centered Systems, Stuttgart, Schattauer

Ballester, L. Nadal, A. and Amer, J. (2014) Métodos y Técnicas de Investigación Educativa, Palma: Edicions UIB

Bodin, M. and Strandberg, A. K. (2011) The Örebro prevention programme revisited: a cluster-randomized effectiveness trial of programme effects on youth drinking. Addiction, 106, 2134-2143

Bullock, B. M. and Forgatch, M. S. (2005) Mothers in transition: Model-based strategies for effective parenting, in Pinsof, W.M. and Lebow, J.L. (Eds.), Family Psychology: The Art of the Science. New York: Oxford University Press

Byrnes, H. Miller, B. Aalborg, A. and Keagy, C. (2012) The relationship between neighborhood characteristics and recruitment into adolescent family-based substance use prevention programs. The Journal of Behavioral Health Sciences \& Research, 39, 174-189

Byrnes, H. Miller, B. Aalborg, A. Plasencia, A. and Keagy, C. (2010) Implementation fidelity in adolescent family-based prevention programs: relationship to family engagement. Health Education Research, 25, 531-541

Coombes, L. Allen, D. Marsh, M. and Foxcroft, D. (2009) The Strengthening Families Programme (SFP) 10-14 and substance misuse in Barnsley: the perspectivess of facilitators and famílies. Child Abuse Review, 18, 41-59

Cullen, F.T. and Jonson, C.L. (2009) Understanding the importance of communities that care. Archives of Pediatrics and Adolescent Medicina, 163, 866-868

Dishion, T. J. Connell, A. Weaver, C. Shaw, D. S. Gardner, F. and Wilson, M. (2008) The Family Check-Up with high risk indigent families: Preventing problem behavior by increasing parents' positive behavior support in early childhood. Child Development, 79, 1395-1414

Ennett, S. T. Jackson, C. Choi, S. Hayes, K. A. Dickinson, D. M. and Bowling, J. M. (2016) A parenting program to promote an alcohol-free childhood: influence on parents' readiness to prevent child sipping. Journal of Studies on Alcohol and Drugs, 77, 327-336

Fernández-Artamendi, S. Fernández-Hermida,J.R. Godley, M. D. and Secades-Villa, R. (2014) Evidence-based treatments for adolescents with cannabis use disorders in the spanish public health system. Journal of Clinical and Health Psychology, 14, 186-194

Fleming, C. Mason, A. Haggerty, K. Thompson, R. Fernandez, K. Casey-Goldstein, M.,... Oats, R. (2015) Predictors of participation in parenting workshops for improving adolescent behavioral and mental health: results from the common sense parenting trial. Journal Primary Prevention, 36, 105-118

Forgatch, M. S. Bullock, B. M. and Patterson, G. R. (2004) From theory to practice: Increasing effective parenting through role play. The Oregon Model of Parent Management Training (PMTO), in Steiner, H., Chang, K., Lock, J. and Wilson, J. (eds) Handbook of Mental Health Interventions in Children and Adolescents: An Integrated Development Approach. San Francisco: JosseyBass

Gewin, A.M. and Hoffman, B. (2016) Introducing the cultural variables in school-based substance abuse prevention. Drugs: Education, Prevention and Policy, 23, 1-14 
GIFES (2018) GIFES-Investigación y formación educativa y social. Palma: Gifes UIB. http:// gifes.uib.es/

Gonzales, N. Dumka, L. Millsap, R. Gottschall, A. McClain, D. Wong, J., and Carpentier, F. (2012) Randomized trial of a broad preventive intervention for mexican american adolescents. Journal of Consulting and Clinical psychology, 80, 1-16

Gottfredson, D. Cook, T. Gardner, F. Gorman-Smith, D. Howe, G. Sandler, I., and Zafft, K. (2015) Standards of evidence for efficacy, effectiveness, and scale-up research in prevention science: next generation. Prevention Science, 16, 893-926

Gutiérrez, A. (2007) Drogodependencias y Trabajo Social. Madrid: Ediciones Académicas

Hawkins, J. D. and Shapiro, V. (2011) Disseminating effective Community prevention practices: opportunities for social work education, Res. Soc. Work Pract., 20, 518-527

Hoge, M.A. Huey, L.Y. and O'Connell, M.J. (2004) Best practices in behavioral health workforce education and training. Administration and Policy in Mental Health, 32, 91-106

Hooven, C. Pike, K. and Walsh, E. (2013) Parents of older at-risk youth: a retention challenge for preventive intervention. Journal Primary Prevent, 34, 423-438

Hooven, C. Walsh, E. Willgerodt, M. and Salazar, A. (2011) Increasing participation in prevention research: strategies for youths, parents, and schools. Journal of Child and Adolescent Psychiatric Nursing, 24, 137-149

Howell, J.C. (2009) Preventing and Reducing Juvenile Delinquency: a Comprehensive Framework. Thousand Oaks: C.A., 2nd ed. Sage

Jiménez, A. (2016) El papel del trabajador social en los equipos integrales de los centros ambulatorios de atención a drogodependientes en la Comunidad de Madrid (Tesis doctoral) Universidad Complutense de Madrid, Madrid

Jones, D. Foster, S. Olson, A. Forehand, R. Gaffney, C. Zens, M. and Bau, J. J. (2007) Longitudinal retention of families in the assessment of a prevention program targeting adolescent alcohol and tobacco use. The utility of an ecological systems framework. Behavior Modification, 31, 638-659

Kolovelonis, A. Goudas, M. and Theodorakis, Y. (2016) Examining the effectiveness of the smoking prevention program 'I Do Not Smoke, I Exercise' in elementary and secondary school settings. Health Promotion Practice, 17, 827-835

Koning, I. M. and Vollebergh, W. A. M. (2016) Secondary effects of an alcohol prevention program targeting students. Journal of Substance Abuse Treatment, 67, 55-60

Kumpfer, K. L., DeMarsh, J. P., and Child, W. (1989) Strengthening Families Program: Children's Skills Training Curriculum Manual, Parent Training Manual, Children's Skill Training Manual, and Family Skills Training Manual. Salt Lake City: University of Utah

Kumpfer, K. Magalhães, C. and Xie, J. (2016) Cultural Adaptation and Implementation of Family Evidence-Based Interventions with Diverse Populations. Prevention Science, 17, 649-659

Kumpfer, K. Xie, J. and O'Driscoll, R. (2012) Effectiveness of a culturally adapted Strengthening Families Program 12-16 years for high-risk irish families. Child Youth Care Forum, 41, 173-195

Kumpfer, K.L. and DeMarsh, J. (1985) Genetic and family environmental influences on 
children of drug abusers. Journal of Children in Contemporary Society, 18 (1-2), 49-91

Leakey, T., Lunde, K.B. Koga, K. and Glanz, K. (2004) Written parental consent and the use of incentives in a youth smoking prevention trial: a case study from project SPLASH. American Journal of Evaluation, 25, 509-523

Lewis, K. Bavarian, N. Snyder, F. Acock, A. Day, J. Dubois, D.L., and Flay, B.R. (2012) Direct and Mediated Effects of a Social-Emotional and Character Development Program on Adolescent Substance Use. Int J Emot Educ, 4, 56-78

Martín, V. M. (2009) Las Drogas entre nosotros. Una mirada desde la educación social. Málaga: Ediciones Aljibe

Miller, B. Aalborg, A.E. Byrnes, H. F. Bauman, K. and Spoth, R. (2012) Parent and child characteristics related to chosen adolescent alcohol and drug prevention program. Health Education Research, 27, 1-13

Nevot, L. (2017) La Implicación Parental en Programas de Competència Familiar. IRIE UIB [Accessed 22 May 2019 at http://irie.uib.cat/files/jornades/comunicacions]

Nevot, L. Ballester, L. and Vives, M. (2018) La implicación parental en los programas de competencia familiar: una revisión sistemàtica exploratoria, in Roig-Vila, R. (ed), El Compromiso Académico y Social a través de la Investigación e Innovación Educatives en la Enseñanza Superior. Barcelona: Editorial Octaedro

O'Connell, M.E. Boat, T. and Warner, K.E. (2009) Preventing Mental, Emotional, and Behavioral Disorders among Young People: Progress and Possibilities. Washington DC: National Academic Press

Ordóñez, D.I. and Bracamonte, P. (2005) Consideraciones para el Diseño y Evaluación de Programas y Proyectos sobre Trabajo Infantil y de Adolescentes. Washington, D.C.: Banco Internacional de Desarrollo

Organización Mundial de la Salud (2019) Organización Mundial de la Salud. Ginebra: World Health Organization. https://www.who.int/es

Orte, C. and GIFES. (2005a) Los programas de prevención de drogas centrados en la familia: una visión desde la investigación y la práctica. Revista Proyecto, 53, 14-17

Orte, C. and GIFES. (2005b) Una investigació educativa sobre un programa de competencia familiar. Anuari de l'Educació de les Illes Balears, 284-295. Palma: Fundació Guillem Cifre de Colonya

Orte, C. Ballester, L. Amer, J. and Vives, M. (2014) Asessing the role of facilitators in evidencebased family-centric prevention programs via delphi technique. Families in Society: The Journal of Contemporary Social Services, 95, 236-224

Orte, C. Ballester, L. Amer, J. and Vives, M. (2017) Training of practitioners and beliefs about family skills in family-based prevention programmes. British Journal of Guidance E Counselling, 45, 573-582

Orte, C. Ballester, L. and Amer, J. (2015) Evaluación de las técnicas de implicación familiar en el desarrollo de programas de competencia familiar, in AIDIPE (ed), Investigar con y para la Sociedad. Cádiz: Bubok

Orte, C. Ballester, L. Pascual, B. Gomila, M.A. and Amer, J. (2016) Las competencias de los formadores en el Programa de Competencia Familiar, un programa de educación familiar 
basado en la evidencia. Revista Complutense de Educación, 29, 651-663

Orte, C. Touza, C. Ballester, L. and March, M. (2008) Children of drug-dependent parents: prevention programme outcomes. Educational Research, 50, 249 - 260

Paniagua, R., Lázaro, S. and Rubio, E. (2010) Cambios y evolución del Trabajo social en España en el final del siglo XX. Miscelánea Comillas, 68(132), 161-184

Prinz, R.J. and Miller, G.E. (1996) Parental engagement in interventions for children at risk for conduct disorder, in Peters, R.D. and McMahon, R.J. (Eds.), Preventing Childhood Disorders, Substance Abuse, and Delinquency. Thousand Oaks: CA, Sage

Rankin, L. Ayers, S. Baldwin, A. and Marsella, F. F. (2016) Delaying youth substance-use initiation: a cluster randomized controlled trial of complementary youth and parenting interventions. Journal of the Society for Social Work \& Research, 7, 177-200

Segrott, J. Gillespie, D. Humphreys, I. Murphy, S. Phillips, C. Reed, H.,...Moore, L. (2014) Preventing substance misuse: study protocol for a randomised controlled trial of the Strengthening Families Programme 10-14 UK (SFP 10-14 UK) BMC Public Health, 17, 1-21

Siefert, K. (1983) An exemplar of primary prevention in social work. Social Work in Health Care, 9, 87-103

Smokowski, P.R. Guo, S. Evans, C.B.R. Wu, Q. and Cotter, K.L. (2016) Evaluating Dosage Effects for the Positive Action Program: How Implementation Impacts Internalizing Symptoms, Aggression, School Hassles, and Self-Esteem. American Journal of Orthopsychiatry, 86, 310-322

Spoth, R., Guyll, M. and Shin, C. (2009) Universal intervention as a protective shield against exposure to substance use: long-term outcomes and public health significance. American Journal of Public Health, 99, 2026-2033

Spoth, R., Redmond, C., Trudeau, L. and Shin, C. (2002) Longitudinal substance initiation outcomes for a universal preventive intervention combining family and school programs. Psychology of Addictive Behaviors, 16, 129-134

Substance Abuse and Mental Health Services Administration. (2018) 2018 National Survey on Drug Use and Health: Prescription Drug Images for the 2018 Questionnaire. Rockville, Maryland: Substance Abuse and Mental Health Services Administration

Woolf, S.H. (2006) The big answer: rediscovering prevention at time of crisis in healthcare. Harvard Health Policy Review, 7, 5-20 